\title{
Why Advertising Does Not Cause Smoking Initiation
}

Lucy L. Henke, (Email: U Email: 1lh6780@ louisiana.edu), University of Louisiana, Lafayette Gwen Fontenot, (Email: Email: fontenotg@aol.com), University of Louisiana, Lafayette

\begin{abstract}
Several charges have been leveled against advertising as the cause of smoking initiation among both young people and adults, but an examination of the relevant literature indicates that advertising is not the cause of smoking initiation. The present study is an examination of the role of advertising in the consumer decision making process generally, and specifically with regard to decisions about smoking.
\end{abstract}

\section{INTRODUCTION}

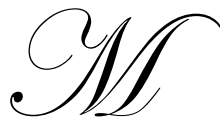

arketing managers face a considerable challenge in their job of conveying brand meaning to consumers. For completely new product categories, the task is easier than for product categories with which consumers are already familiar. After all, we all know what automobiles are, we know how they are used, and we have more than likely developed preferences for particular makes and models which we find consistent with our own attitudes and values. A marketing manager may have difficulty getting through to young, active, college-age males with the message that minivans are cool-to-drive symbols of virility, because their personal experience tells them otherwise. On the other hand, we may have looked to the manufacturers of MP3 players and wireless communication devices for information about what those devices are, how they work, and how they fit into our lives. Eventually we may have turned to friends who know more than we do about Blackberries and Palm Pilots, to get a better understanding of which makes and models best address our personal needs and reflect our lifestyles. Ultimately, our decision about which model to buy, if any, rests on a multitude of factors, the least of which is advertising.

\section{FACTORS WHICH INFLUENCE CONSUMER BEHAVIOR}

Consumer behavior is highly individualized and complex, and is influenced by a multitude of intrapersonal, interpersonal, and external mediated factors. (See, for example, Pride and Ferrell 1997; Schiffman and Kanuk, 2000; Semenik 2002). Intrapersonal factors include variables such as one's individual personality characteristics, one's individual drives and motivations, and one's values, attitudes, and beliefs. Interpersonal factors include personal interactions with others, especially family members and peers, as well as interactions with members of groups to which one belongs or aspires to belong, such as one's culture, subculture or subcultures, reference groups, and the like. External mediated factors would include nonpersonal sources of information such as newsletters, television portrayals, advertising, and other mass-mediated information.

Intrapersonal factors determine the way in which a consumer will perceive and interpret information. (See, for example, Kotler and Armstrong 1994; Schiffman and Kanuk 2000; Semenik 2002.) A consumer's personal values, attitudes, and beliefs, individual personality characteristics and character traits, and drives and motivations are unique. They vary across individuals (some people are risk-seekers, others risk-averse), vary across situations (I like to shop at Albertson's Supermarket, but not for Christmas gifts), and vary over time (one is motivated by hunger before a meal, but not afterward), thus ensuring that a consumer's response to any consumer situation is highly individualized and specific to the context in which the situation occurs. These intrapersonal factors combine to determine how a consumer will interpret incoming stimuli, and respond to his or her own unique interpretation. 
Consumer behavior is greatly influenced by interpersonal factors. Personal interaction with others, particularly family and peers, socializes an individual with regard to the expectations of one's culture, subculture or subcultures, reference groups, and other groups to which one belongs or aspires to belong. (See, for example, Kotler and Armstrong 1994; Pride and Ferrell 1997; Schiffman and Kanuk 2000). Through observation and interaction within the family, one learns at a very early age about the core values of one's culture. In an American household, for example, one learns that success comes from hard work; that self-reliance is something to aspire to; that freedom of choice is a privilege to be cherished; that being "young at heart" is important, among other values. Through observation and interaction within the family, one learns about the expectations of the subcultures to which one belongs, such as subcultures based on ethnicity, religion, geographic region, social class, special interests, or others. Experiences within the family shape one's values, attitudes, and beliefs.

External mass-mediated messages, including advertising, have the least impact on individual consumers because these messages are filtered through interpersonal communication channels as well as consumers' own perceptual systems before they can acquire meaning. (See, for example, Kotler and Armstrong 1994, pp. 469-70; Lazarsfeld, Berelson, and Gaudet 1948, p. 151; Schiffman and Kanuk 2000, pp. 129-35; Wells, Burnett, and Moriarty 1995, pp. 182-3.) Such messages do not have inherent meaning on their own, but rather attempt to resonate with a preexisting set of values, beliefs and attitudes. Ads follow, they do not lead.

A content analysis of an advertisement, for example, is just that and nothing more-a simple description of the content of the message. It is not an indication of the meaning of the message, nor is it a reflection of the perceptions of the message for any individual other than the person providing the analysis. No person is able to identify the precise meaning of any message for another person. Rather, each consumer determines the meaning of these messages based on the pre-existing values, attitudes, motivations, and beliefs the consumer brings to the message. As the authors of a recent advertising text write:

Remember, the meaning of an ad does not exist inviolate and immutable within its borders. In fact, it doesn't exist there at all. Meaning is constructed in the minds of consumers, not delivered by advertisements. What an ad means is determined through a subtle but powerful process of meaning construction by consumers (O'Guinn, Allen, and Semenik 2003, page 202).

Whether a message is considered appealing depends on a myriad of factors including the individual's experiences with, attitudes toward, and beliefs about the product and the brand being advertised, the perceived content of the message, the context of the message, the medium in which the message appears, and so forth.

Any given advertisement means different things to different people because of the wide variation in individual perception. Obviously, the only way to determine the precise effect of any given advertisement is to conduct an individual analysis to assess the perceptions of class members.

\section{THE CONSUMER DECISION MAKING PROCESS}

Individuals, both adults and adolescents, progress through a series of stages in making a consumer decision (See, for example, Belch and Belch 2001, pp. 108-124; Kotler and Armstrong 1994, pp. 164-171; Pride and Ferrell 1997, pp. 133-136; Schiffman and Kanuk 2000, p. 449). Marketing communication campaigns have used the consumer decision making process as a framework for determining strategic objectives. (See, for example, Kotler and Armstrong 1994, pp. 466-468; Schultz 1990, p. 61; Wells, Burnett, and Moriarty 1995, pp. 247-248.) First, the prime prospect or target of a campaign needs to be aware of the brand name of your product or service, and understand that the brand name represents a particular product category. Second, the target consumer should perceive relevant information about the brand. What is relevant depends on the individual and the situation but may include such things as features, benefits, availability, price, and so forth. Third, the target consumer must perceive the information about the brand to be positive. Fourth, the target consumer should perceive that the brand is unique and better than the competition in important ways. The advertising should help consumers differentiate among brands, and determine that the advertised brand is the preferred brand due to its unique qualities. Fifth, the consumer should have the conviction 
to buy your advertised brand instead of any other. Finally, following the purchase, the provider of the brand must reinforce the target consumer's decision to buy the brand.

\section{THE ROLE OF ADVERTISING IN THE CONSUMER DECISION MAKING PROCESS}

Consumers encounter vast amounts of advertising on a daily basis - estimates vary, but consumers are reported to see upwards of 3000 ad messages every day (www.rab.com/station/whyradio/foundseven.html). In order to make sense of their busy, complicated environment, consumers of all ages filter out a great deal of information, including advertising, that is irrelevant to their lives, and perceive information which reinforces their pre-existing values, attitudes, and beliefs. In order for advertising to have any impact, therefore, it must break through the advertising "clutter" and, specifically, break through the target consumer's perceptual barrier. Relevance, originality, and repetition will increase the odds that a mass-mediated message will be perceived by a target consumer. Consumer research has shown that advertising can be effective in the early stages of the consumer decision making process in enhancing consumer awareness and knowledge of a brand; however, later stages of the process, including the decision to purchase a brand, are shown to be influenced by interpersonal factors. As Kotler and Armstrong note in their marketing text:

Although it reaches many people quickly, advertising is impersonal and cannot be as persuasive as a company salesperson....Personal selling is the most effective tool at certain stages of the buying process, particularly in building up buyers' preferences, convictions, and actions (Kotler and Armstrong 1994, pp. 474-5).

The effectiveness of advertising in imparting information about a product or service depends on the consumer's previous understanding of the product or service. For that reason, the role of advertising for imparting information about totally new products and services differs from its role in communicating about known products and services. Totally new products - innovations - are introduced to all consumers of all ages at the same time. Advertising about these products and services imparts information about how the new product could be used, how it could be relevant, and so forth. Mature products are not new, and advertising for mature products need not explain how the products are used because consumers have observed the products in their daily lives prior to viewing advertising for it. Advertising for mature products must impart information about how the advertised brand is better for the target consumer than, and differs from, other brands in the product category.

\section{THE ROLE OF BRAND ADVERTISING IN A MATURE CONSUMER PRODUCT MARKET}

It is well established in the field of marketing communications that in a mature product market, the function of advertising and promotion is primarily to maintain brand loyalty among a brand's consumers, and to influence decisions of consumers of competing brands to switch to the advertised brand.

Marketing practitioners and researchers recognize the concept of a "mature product market." Most consumer products pass through a product "life cycle." When a new product category is introduced (e.g., DVD players today, personal computers nearly twenty years ago), most consumers do not know what the product is, what its characteristics are and whether the product is useful or desirable. The purpose of advertising and promotion at this introductory stage is to stimulate demand for a product category regardless of brand. As the authors of a recent marketing text write:

When an organization is the first to introduce an innovative product, it tries to stimulate primary demand - demand for a product category rather than for a specific brand of product —-through pioneer promotion.

Pioneer promotion informs potential customers about the product: what it is, what it does, how it can be used, and where it can be purchased. Because pioneer promotion is used in the introductory stage of the productlife cycle, which means that there are no competing brands, it neitheremphasizes brand names nor compares brands. The first company tointroduce the compact disc player, for instance, initially attempted tostimulate primary demand by 
emphasizing the benefits of compact discplayers in general rather than the benefit of its specific brand (Pride and Ferrell 1997, page 398).

For consumers, this type of advertising may be an important source of product information because other sources of information - e.g., personal experience with the product, the experiences of friends and family members, images of product use in the media - are lacking as a result of the product's novelty. It is also significant that at this stage, all potential consumers, young and old alike, learn about the product's attributes at roughly the same time.

As a product category matures, advertising takes on a different role and purpose - from stimulating primary demand for the product category to stimulating "selective demand"; i.e. maintaining or shifting consumer demand and preference for particular brands. For example, because chewing gum is a mature product, consumers learn at a very early age from their families and their first-hand experience what chewing gum does and for what activities chewing gum is useful. People do not rely on advertisements to inform them of the function of chewing gum (or a VCR or a toothbrush) in the first instance. The market for such products has matured and the purpose of advertising in such a market is to persuade those who have already decided to use the product to select the advertised brand. The focus is brand differentiation. Advertising in a mature market is designed to emphasize the differences between available brands, and to heighten the perceived attractiveness of the unique properties of one's brand.

It is very difficult for a marketer in a mature product market to affect aggregate demand for that product category. An example of an attempt to do so is the campaign sponsored by the American dairy industry to increase overall consumption of milk. While the "celebrity milk mustache" advertising and the "Got milk?" catchphrase have achieved high awareness, the campaign apparently has not resulted in increased milk consumption. In fact, consumption has declined every year during the time of this campaign (O'Guinn, et al. 2000; Marketing News 1998). This lack of success is not surprising in light of what we know about consumer decision making. A consumer's decision whether to drink milk will be affected far more by whether the consumer likes the taste of milk and on whether family and friends drink milk than on even a very clever and engaging advertising campaign. Thus, even where a campaign is specifically designed to stimulate demand for a product category, it is very difficult through advertising to affect aggregate demand for a mature product, even where that campaign achieves high awareness and generates favorable reviews. A campaign designed to promote a specific brand is even less likely to have such an effect.

\section{THE MARKET FOR TOBACCO PRODUCTS IS MATURE}

Cigarettes are a classic example of a mature, indeed declining, consumer product market in which advertising is entirely brand advertising that seeks to stimulate selective demand for particular brands. In a mature or declining market, sellers are competing for market share and the goals of advertising and promotion are to persuade consumers of competing products to switch to the advertised brand as their primary or alternate brand choice while, first and foremost, maintaining the brand loyalty of existing customers against the efforts of competitors to persuade them to switch. In a product market as large as that for cigarettes, even small percentage shifts in market share have huge economic significance. Even a one percent share of such a market represents very substantial revenues and justifies significant expenditures on advertising and promotion to attempt to protect and expand one's market share.

Research in the field of marketing confirms that tobacco advertising serves to stimulate selective, not primary, demand. As Wilcox (Wilcox 1991; Wilcox and Vacker 1992) and others have shown, there is no evidence that cigarette advertising does anything other than differentiate brands. Sturgess (1982) confirms the finding that cigarette advertising, which takes place in a mature product category, serves to stimulate selective demand. As one advertising text reports, "[v]ast amounts of money spent on advertising and publicity to promote a given brand of cigarettes will not persuade a non-smoker to smoke" (Darmon and Laroche 1985).

The conclusions are consistent with a report by the Federal Trade Commission, the government agency with the broadest power and responsibility to regulate adverting, which reported that cigarette company advertising has little or no effect on total cigarette consumption (Federal Trade Commission 1985). They are also consistent with the 
testimony of Daniel Oliver, the Chairman of the Federal Trade Commission before the Transportation Subcommittee of the House Committee on Energy and Commerce on April 3, 1987: "Far from stimulating overall demand by conveying new information to consumers about the uses of tobacco generally, tobacco advertising is likely to have its predominant impact in affecting the consumers' selection among competing brands" (Oliver 1987).

Similarly, a report from the United States Bureau of Economics concluded that the available research has not identified advertising as a significant stimulant to the aggregate demand for cigarettes, consistent with the assertion that advertising in the cigarette industry serves mainly to reallocate demand among brands (Mulholland 1989).

\section{SMOKERS CONSISTENTLY FAIL TO IDENTIFY ADVERTISING AS A REASON FOR SMOKING BUT THEY DO IDENTIFY ADVERTISING AS A REASON FOR CHOOSING A BRAND}

Studies of smokers confirm that advertising stimulates selective rather than primary demand. Years of polling research by The Gallup Organization indicate that the majority of people begin smoking because of peer influence and parental modeling, not advertising (Gallup Poll 1991; Larsen 1993; Larsen 1994). Intrapersonal factors such as curiosity and rebelliousness are also cited as motivating factors in the decision to begin smoking.

Advertising, however, is cited as a major influence on brand choice. Zinser (1994) asked smokers why they began smoking and why they chose their brand of cigarettes. Reasons for starting to smoke, consistent with the Gallup data, include peer and parent influence rather than advertising. On the other hand, when respondents were asked about the influence that advertising had on brand choice, advertising came in third out of five factors. Smokers are aware of, and willing to identify, the type of influence that advertising has on their smoking-related decisions.

\section{SUMMARY}

Consumer decision making is complex and is based on a myriad of factors, many of which are not under the control of marketing managers. Personality characteristics and personal experiences determine how commercial communications from brand managers will be received and interpreted, and the strongest shaper of individual values, attitudes, and beliefs is interpersonal interaction with others, especially family and peers. Advertising is but one of the sources of information about products and services which is available to consumers. Unfortunately for brand managers, although advertising is easy to control, consumer response to advertising cannot be controlled. Consumers use advertising to suit their needs, and based on the evidence, consumers do not use advertising to make decisions about whether or not to begin smoking. There is no evidence that the advertising or promotion of tobacco products has any measurable effect on the initiation of tobacco use, that it increases aggregate tobacco consumption, that it prevents or slows a decline, or does anything other than influence brand selection.

\section{SUGGESTIONS FOR FUTURE RESEARCH}

Future studies might attempt to identify and quantify the impact of factors other than advertising on decisions about smoking. In-depth reconstructions of the decision to first smoke a cigarette among present smokers as well as present nonsmokers, comprehensive examinations of affiliation with smokers within and without one's household, and investigation of the evolving perceptions of smoking and cigarettes among individuals from smoking and nonsmoking households over time might all provide insights into the myriad of factors on which smoking decisions are based. 


\section{REFERENCES}

1. Belch, George E. and Michael A. Belch (2001), Advertising and Promotion: An Integrated Marketing Communication Perspective (Fifth Edition), New York: McGraw-Hill/Irwin.

2. Darmon, Rene and Michel Laroche (1985), Advertising Management in Canada, Toronto: John Wiley \& Sons, Inc.

3. Federal Trade Commission (1985), "Recommendations of the Staff of the Federal Trade Commission: Omnibus Petition for Regulation of Unfair and Deceptive Alcoholic Beverage Advertising and Marketing Practices", March 1985, Docket, No. 209-46, 1-52, with Appendix A.

4. Gallup Poll (1991), "Public Opinion 1991".

5. Kotler, Philip, and Gary Armstrong (1994), Principles of Marketing (Sixth Edition), Englewood Cliffs, New Jersey: Prentice-Hall, Inc.

6. Larsen, M., et al. (1993), "Smoking Prevalence and Attitudes Towards Smoking Among Adults", Gallup.

7. Larsen, M., et al. (1994), "Smoking Prevalence and Attitudes Towards Smoking Among Adolescents", Gallup.

8. Lazarsfeld, P.F., B. Berelson, and H. Gaudet (1948), The People's Choice (Second Edition), New York: Columbia University Press.

9. Marketing News (1998), "Got Results?”, March 2, 1.

10. Mulholland, Joseph P. (1989), "The Effect of Advertising on the Level and Composition of Cigarette Consumption", November 13, 1989.

11. O'Guinn, Thomas, Chris Allen, and Richard Semenik (2000), Advertising (Second Edition), USA: Southwestern Publishing.

12. O'Guinn, Thomas, Chris Allen, and Richard Semenik (2003), Advertising and Integrated Brand Promotion (Third Edition), Mason, Ohio: South-Western Publishing.

13. Oliver, Daniel (1987), "Prepared Statement of Daniel Oliver, Chairman, Federal Trade Commission, on Cigarette Advertising Bans", April 3, 1987.

14. Pride, William and O.C. Ferrell (1997), Marketing: Concepts and Strategies, Boston: Houghton Mifflin Company.

15. Schiffman, Leon G., and Leslie Lazar Kanuk (2000), Consumer Behavior (Seventh Edition), Upper Saddle River, New Jersey: Prentice-Hall, Inc.

16. Schultz, Don (1990), Strategic Advertising Campaigns (Third Edition), Chicago: NTC Business Books.

17. Semenik, Richard J. (2002), Promotion and Integrated Marketing Communications, Cincinnati, Ohio: South-Western Publishing.

18. Sturgess, Brian (1982), "Dispelling the Myth: The Effects of Total Advertising Expenditure on Aggregate Consumption", Advertising \& Markets, J.C. Luik and M.J. Waterson (eds.), United Kingdom: NTC Publications Limited, 29-42.

19. Wells, William, John Burnett, and Sandra Moriarty (1995), Advertising: Principles and Practice (Third Edition), Englewood Cliffs, New Jersey: Prentice-Hall, Inc.

20. Wilcox, Gary (1991), "Cigarette Brand Advertising and Consumption in the United States: 1949-1985", Journal of Advertising Research, August/September, 61-67.

21. Wilcox, Gary and Barry Vacker (1992), "Cigarette Advertising and Consumption in the United States: 19611990", International Journal of Advertising, 11, 269-278.

22. www.rab.com/station/whyradio/foundseven.html (2002), retrieved June.

23. Zinser, Otto, Russ Kloosterman, and Alicia Williams (1994), "Advertisements, Volition, and Peers Among Other Causes of Smoking: Perceptions of College Student Smokers”, Journal of Alcohol and Drug Education, 39 (3), 13-36. 